\title{
Strain rate-strain/stress relationship during isothermal forging: A Deform-3D FEM
}

\author{
Japheth Obiko $^{a}$, Fredrick Mwema ${ }^{\text {b,c* }}$ and Esther T. Akinlabi ${ }^{\mathrm{c}}$
}

${ }^{a}$ Jomo Kenyatta University of Agriculture \& Technology, Nairobi, Kenya
${ }^{b}$ Dedan Kimathi University of Technology, Private Bag, Nyeri, Kenya

${ }^{c}$ University of Johannesburg, Auckland Park Campus, Johannesburg, South Africa

\begin{tabular}{l}
\hline A R T I C L EI N F O \\
\hline Article history: \\
Received 24 August, 2019 \\
Accepted 15 September 2019 \\
Available online \\
15 September 2019 \\
\hline Keywords: \\
Deformation \\
DeformTM-3D \\
Hot forging \\
Strain rate
\end{tabular}
\begin{abstract}
A B S T R A C T
A Deform ${ }^{\mathrm{TM}}-3 \mathrm{D}$ analysis was used to illustrate the effect of strain rate on isothermal deformation (forging) of X20CrMoV121 steel. The simulation process was conducted at an isothermal temperature of $850{ }^{\circ} \mathrm{C}$ and varying the strain rates of $1.9 \mathrm{~s}^{-1}, 2 \mathrm{~s}^{-1}$ and $3 \mathrm{~s}^{-1}$. The results of temperature, strain and stress distribution at various strain rates were reported. The strain/stress distribution exhibited a heterogeneous distribution, indicating inhomogeneity during hot forging. It was also shown that the deformation inhomogeneity decreased with the increase in the strain rate. The results are comparable to experimental publications, indicating that Deform $^{\mathrm{TM}}-3 \mathrm{D}$ is an effective tool for finite element analysis of hot deformation processes.
\end{abstract}

\section{Introduction}

(C) 2020 Growing Science Ltd. All rights reserved.

Forging process is one of the oldest methods for metalworking, which is largely used to achieve a refined and homogeneous microstructure (Equbal et al., 2014). However, it is not practical to achieve a homogeneous microstructure due to the effects of deformation conditions and parameters (Christiansen et al., 2016). During open die forging process, the anvil-workpiece friction resulting from shear stresses lead to heat generation, which cause temperature variations in the deformed sample (Zhang et al., 2009). The change in the forging temperature results in heterogeneous stress and strain distribution which in turn affect the mechanical properties across the deformed sample (Zhang et al., 2009; Evans \& Scharning, 2001). Apart from temperature, other process parameters such as strain rate and punch velocity contribute to the metal flow deformation behavior (Equbal et al., 2014). For in-depth understanding of the forging process, computer modelling through tools (e.g. Deform ${ }^{\mathrm{TM}}-3 \mathrm{D}$ software) is necessary (Yang \& Lin, 2016). FEM simulations can investigate complex interrelationships among various aspects of forging and material characteristics to reliably predict/study metal flow behavior (Lee et al., 2011; Na et al., 2003). The present study reports on the relationship between strain rate and deformation characteristics of hot forging of X20CrMoV121 steel using the Deform ${ }^{\mathrm{TM}}-3 \mathrm{D}$ simulation software. X20CrMoV121 belongs to one of the multi-component martensitic steels and evolution of structure during hot working is complex and difficult to establish its hot working regime. The material is widely used in power plant boiler pipes.

\footnotetext{
* Corresponding author.

E-mail addresses: fredrick.mwema@dkut.ac.ke (F. Mwema)
} 


\section{Finiate element modeling}

The Finite Element Analysis (FEA) is a computational tool used for modelling and simulation of a variety of complex engineering problems. In the metal working industry, Deform ${ }^{\mathrm{TM}}-3 \mathrm{D}$ software is applied to simulate and analyze the metal flow characteristics. Here, computer simulation software (Deform ${ }^{\mathrm{TM}}-3 \mathrm{D}$ version 6.1) was used to study the relationship between strain rate and stress/strain distribution during the deformation of X20CrMoV121 steel.

The finite element model of a short cylindrical specimen, upper and lower punch were quickly modelled using the inbuilt DeformTM-3D geometry primitive module. The dimensions of the short cylinder were $10 \mathrm{~mm}$ diameter and $15 \mathrm{~mm}$ length (which are the same as those used in the physical process in the thermal-mechanical simulators). The meshed and loaded specimens are shown in Fig. 1. The upper and lower punch were considered rigid structure since negligible plastic deformation was expected. The hot deformation process was undertaken at deformation temperature of $850{ }^{\circ} \mathrm{C}$ and at strain rates of $1.9 \mathrm{~s}^{-1}, 2 \mathrm{~s}^{-1}$ and $3 \mathrm{~s}^{-1}$. The simulation parameters used for forging simulation process are shown in Table 1. Similar conditions were used in our previous study (Obiko et al., 2019) and are summarized in Table 1.

Table 1. Simulation parameters used in the forging simulation process

\begin{tabular}{lll}
\hline No. & Simulation parameter & value \\
\hline 1 & Cylinder specimen height $(\mathrm{mm})$ & 15 \\
2 & Cylinder specimen diameter $(\mathrm{mm})$ & 10 \\
3 & Coefficient of friction (shear-type) & 0.3 \\
4 & Deformation environment temperature $\left({ }^{\circ} \mathrm{C}\right)$ & 25 \\
5 & Upper and lower punch $($ dies $)$ temperature $\left({ }^{\circ} \mathrm{C}\right)$ & 250 \\
6 & Conventional coefficient $\left(\mathrm{N} /\left(\mathrm{s} . \mathrm{mm} .{ }^{\circ} \mathrm{C}\right)\right)$ & 0.02 \\
7 & Heat transfer coefficient $\left(\mathrm{N} /\left(\mathrm{s} . \mathrm{mm} .{ }^{\circ} \mathrm{C}\right)\right)$ & 5 \\
8 & Number of deformation steps & 52 \\
9 & Number of elements & 44725 \\
10 & Number of nodes & 9110 \\
\hline 11 & Upper punch velocity $(\mathrm{mm} / \mathrm{sec})$ & 5 \\
\hline
\end{tabular}

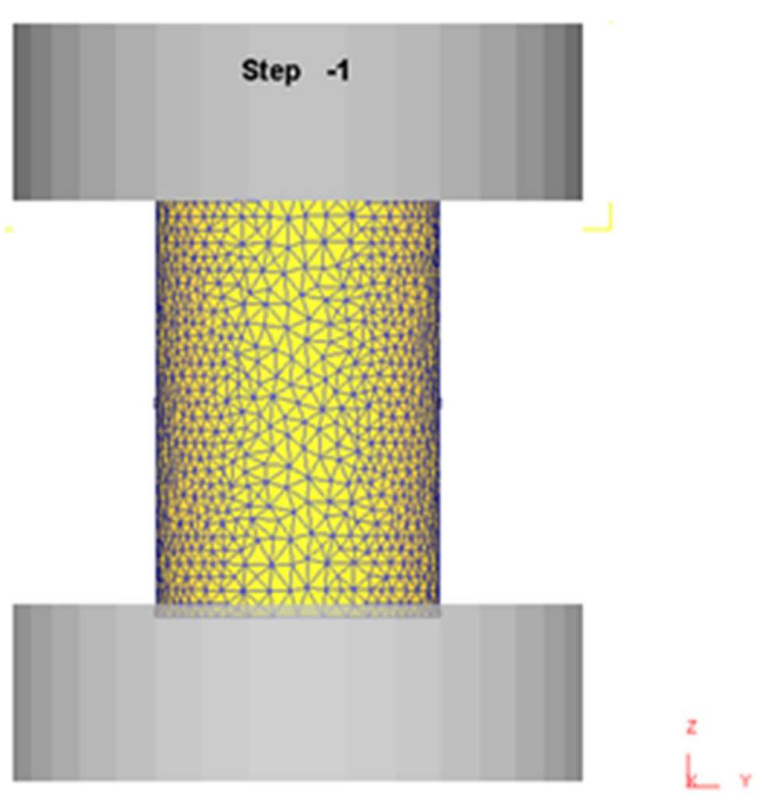

Fig. 1. The finite element model showing the meshed cylinder for the simulation process 


\section{Results and discussions}

\subsection{Load and temperature distribution during hot forging}

The load-time flow curves for the cylindrical billet taken at $1.05 \mathrm{~s}$ during the forging simulation process is shown in Fig. 2. The deformation load exhibits a proportional relationship with the strain rate $\left(1.9-3.0 \mathrm{~s}^{-1}\right)$ at the given temperature $\left(850{ }^{\circ} \mathrm{C}\right)$. This result can be validated by the experimental observations by Zaiemyekeh et al. (2019) in which it was reported that the deformation energy absorbed by the samples during deformation increases with the strain rate. The increase in deformation load with strain rate can be associated with the increase in the deformation energy absorption by the sample during deformation. Fig. 3(a) represents the temperature variation whereas Fig. 3(b) shows the temperature distribution within the sample during the hot forging process at $3 \mathrm{~s}^{-1}$. In this study, there were no significant differences in temperature distribution among the three strain rates and for all the cases points $\mathrm{P} 2$ and $\mathrm{P} 1$ on the sample exhibited the highest and lowest temperature values respectively. The deformation temperature measured across the sample as shown in Fig. 3(a) for the four points (P1, P2, $\mathrm{P} 3$ and $\mathrm{P} 4)$ indicated considerable drops in temperatures in three points (P1, P3 and P4). The top and bottom surface $(\mathrm{P} 1)$ of the interface between the anvil and the billet recorded the highest drop of $220{ }^{\circ} \mathrm{C}$. This was mainly because there was a high-temperature gradient between the two surfaces, hence more heat was rapidly extracted from the billet through the anvil. The chilling effect occurs at this surface (P1) leading to inhomogeneous deformation process (Rasti et al., 2011). Points P3 and P4 had a temperature drop of $40{ }^{\circ} \mathrm{C}$ and $120{ }^{\circ} \mathrm{C}$ respectively whereas Point $\mathrm{P} 2$ had a slight increase in the deformation temperature. The increase in temperature may be due to the heat generation associated with plastic deformation occurring within this region. Furthermore, the standard deviation histogram (Fig. 3b) shows high variation in the deformation temperature during the forging process. These results are indications of heterogeneity in hot forging process.

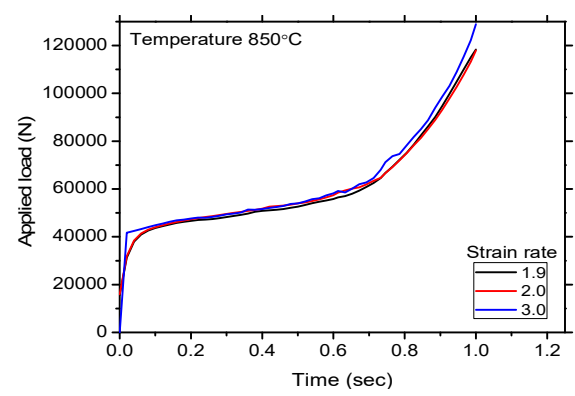

Fig. 2. Load-time curves at different strain rate and forging temperature of $850^{\circ} \mathrm{C}$

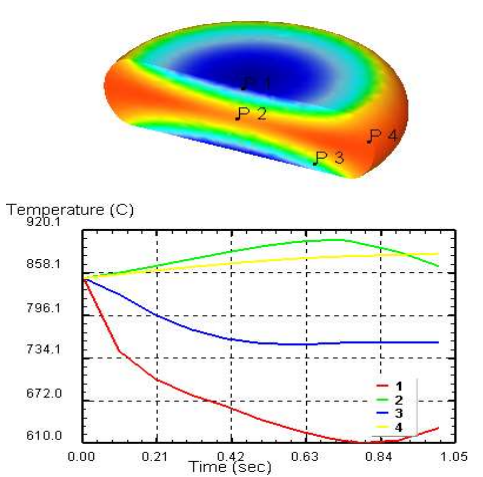

(a)

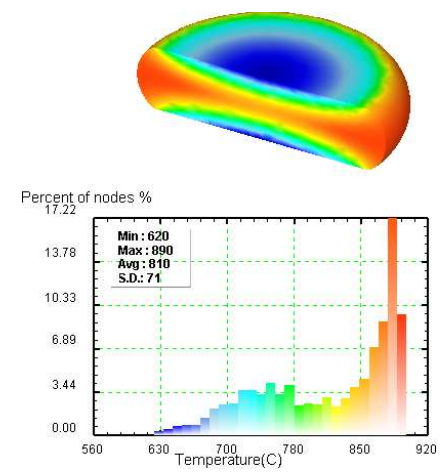

(b)

Fig. 3. (a) Temperature variation at different points (P1, P2, P3 and P4) and (b) Temperature distribution across the sample at strain rate of $3 \mathrm{~s}^{-1}$

\subsection{The effect of strain rate on the stress and strain distribution}

Fig. 4 shows the shape of the billet after deformation and variation of the strain distribution behavior at different strain rates. The histograms (Figs. 4(a), 4(b) and 4(c)) show that the standard deviation decreased as the strain rate increased from 1.9 to $3 \mathrm{~s}^{-1}$. This is because at lower strain rate there are higher frictional forces due to a longer contact between the anvil and the workpiece. The frictional forces lead to change in the deformation temperature and impede plastic deformation, thereby causing heterogeneous deformation (Rasti et al., 2011). The results further indicated that the strain distribution vary across the deformed sample (Fig. 4(d)). As shown, higher deformation was experienced at the center of the deformed billet (point P2) at all strain rates. This region experienced an intense shearing of the microstructure leading to severe plastic deformation. Under this condition, refinement of the grain structure may occur due to dynamic recrystallization softening mechanism (Zhang et al., 2009). 
Fig. 5 shows the variation in the stress distribution in the deformed sample under different strain rates. The average effective stress decreased with the increase in the strain rate as shown in the histograms presented in Figs. 5(a)-5(c). This is contrary to the results reported in the literature which show a direct relationship between deformation stress and strain rate (Wang et al., 2015; Yang et al., 2015; Li et al., 2011). The deviation of the current results with the literature can be due to the friction on the anvil-billet interface, hence stress a correction is required. It was seen that the highest equivalent stress was in the regions which experienced the lower strains (Fig. 5(d)). This is because the deformation process at this region occurs at a lower temperature due to the chilling effects. Therefore, a higher deformation load was required to deform the material. It further indicates that higher flow stress due to softening mechanism was observed in this region (Shi, \& Liu, 2011).
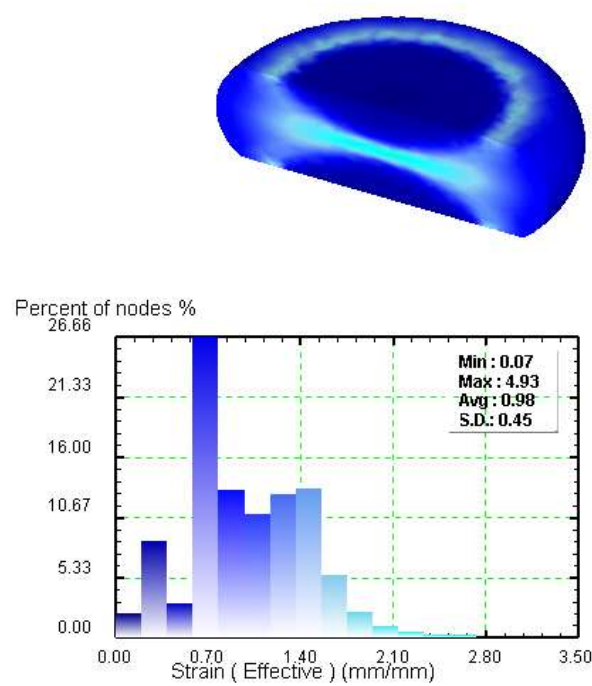

(a)
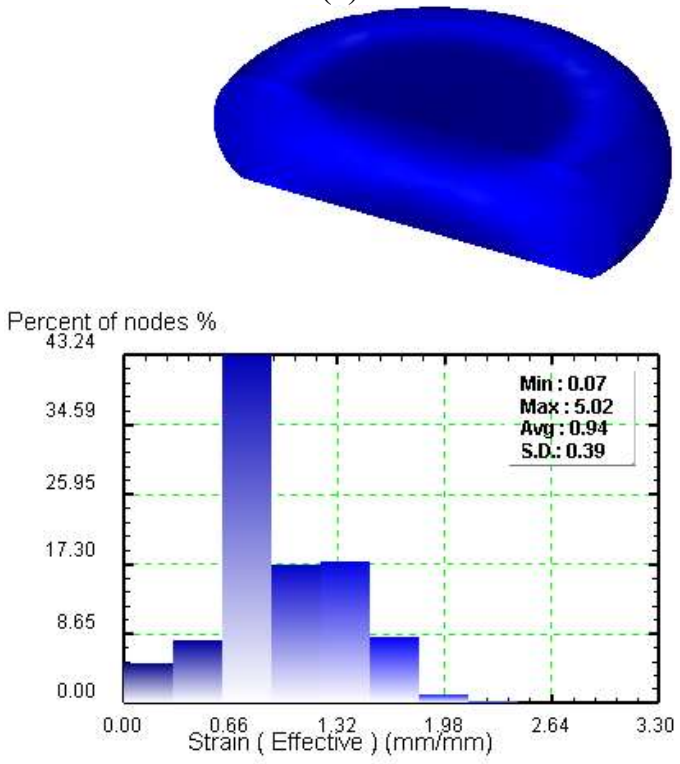

(C)

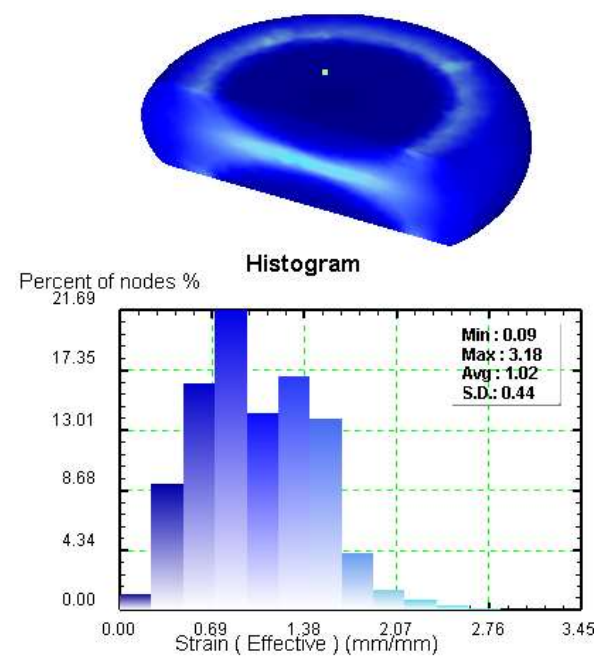

(b)


(d)

Fig. 4. The strain variation in sample after deformation at (a) $1.9 \mathrm{~s}^{-1}$ (b) $2 \mathrm{~s}^{-1}$ (c) $3 \mathrm{~s}^{-1}$ at temperature of $850^{\circ} \mathrm{C}$ (d) the strain distribution at four different points on the deformed sample at $3 \mathrm{~s}^{-1}$ 

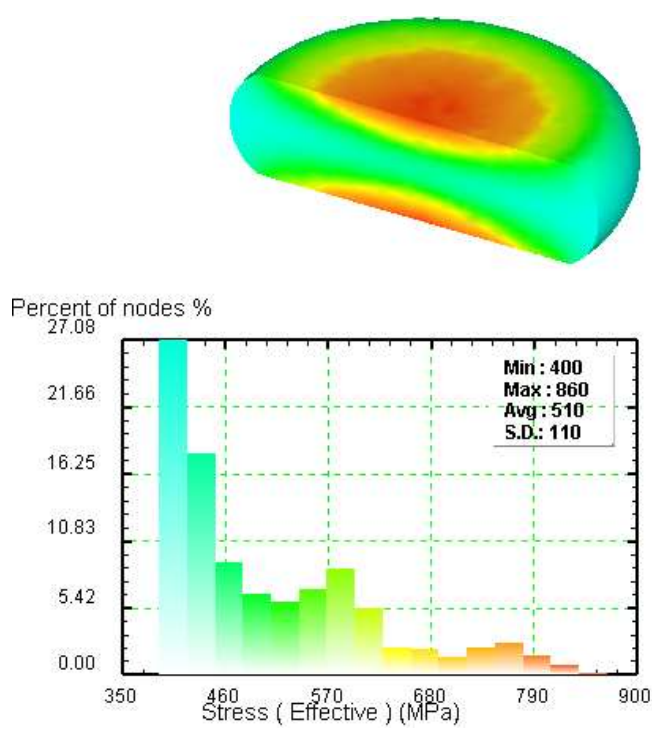

(a)
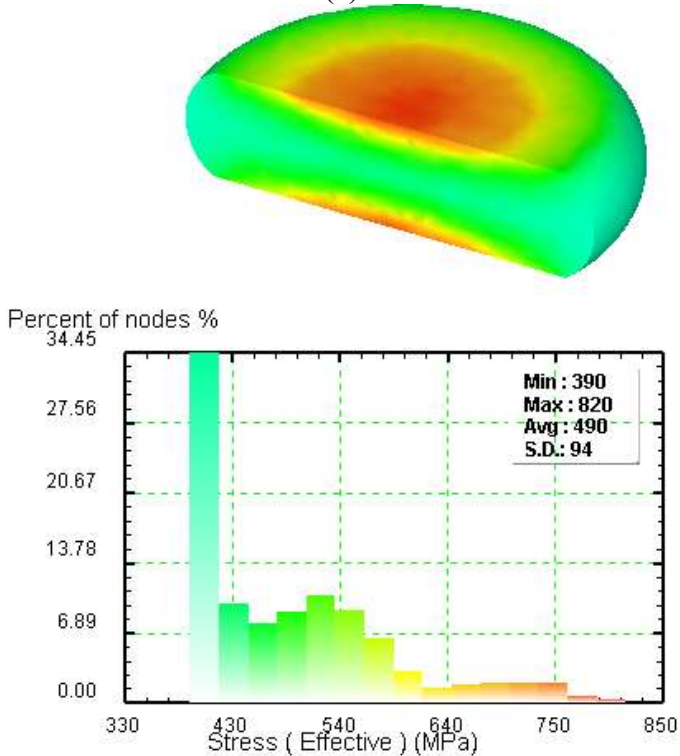

(c)
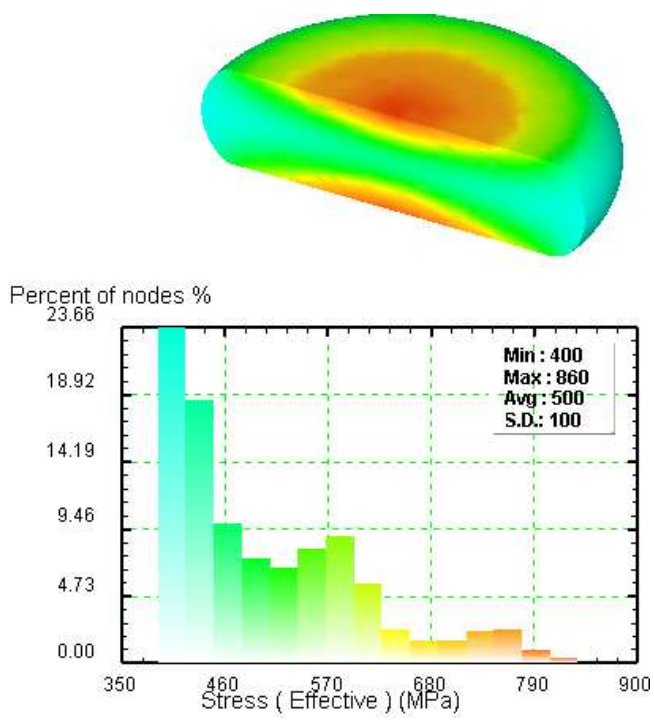

(b)
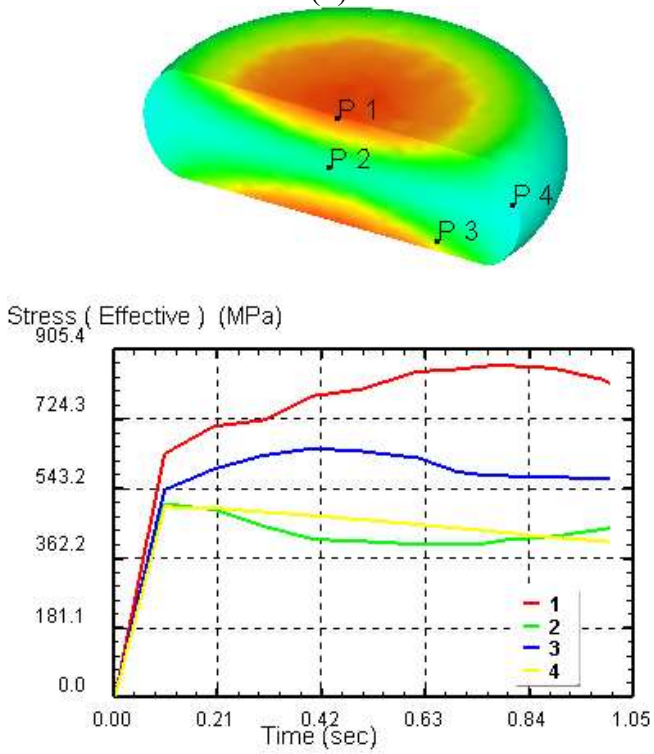

(d)

Fig. 5. The stress variation on the sample after deformation at (a) $1.9 \mathrm{~s}^{-1}$ (b) $2 \mathrm{~s}^{-1}$ (c) $3 \mathrm{~s}^{-1}$ at a temperature of $850^{\circ} \mathrm{C}$ (d) the stress distribution at four different points on the deformed sample at strain rate of $3 \mathrm{~s}^{-1}$

\section{Conclusion}

From the simulation of the forging process using Deform ${ }^{\mathrm{TM}}-3 \mathrm{D}$ software at $850{ }^{\circ} \mathrm{C}$ and varying the strain rate, the following conclusions were drawn:

The temperature distribution during forging simulation of the billet was inhomogeneous. At the anvil-billet contact surface, the temperature decreased rapidly due to the chilling effect. The loadtime flow curves show that the required deformation load capacity increase with the strain rate.

The stress and the strain distribution exhibited an inhomogeneous behavior across the deformed cross-section of the cylindrical billet. The inhomogeneity behavior can be attributed to the change in the deformation temperature and the effect of the friction at the anvil-billet contact surface. High deformation occurred at the mid height of the cylindrical sample (point P2) with the edges recording the lowest strains. The highest stresses occurred in the regions that exhibited the lowest strains. The maximum tensile stress was observed at the edges of the billet which might lead to 
surface cracking. At the anvil and the billet contact surface, high effective stress was recorded which might also enhance deformation defects (Liu et al., 2012).

\section{References}

Christiansen, P., Martins, P. A. F., \& Bay, N. (2016). Friction compensation in the upsetting of cylindrical test specimens. Experimental Mechanics, 56(7), 1271-1279.

Equbal, M. I., Talukdar, P., Kumar, V., \& Ohdar, R. K. (2014). Deformation behavior of micro-alloyed steel by using thermo mechanical simulator and finite element method. Procedia Materials Science, 6 , 674-681.

Evans, R. W., \& Scharning, P. J. (2001). Axisymmetric compression test and hot working properties of alloys. Materials Science and Technology, 17(8), 995-1004.

Lee, Y. S., Lee, S. U., Van Tyne, C. J., Joo, B. D., \& Moon, Y. H. (2011). Internal void closure during the forging of large cast ingots using a simulation approach. Journal of Materials Processing Technology, 211(6), 1136-1145.

Li, H. Z., Wang, H. J., Liang, X. P., Liu, H. T., Liu, Y., \& Zhang, X. M. (2011). Hot deformation and processing map of 2519A aluminum alloy. Materials Science and Engineering: A, 528(3), 1548-1552.

Liu, M. P., Sun, S. C., Roven, H. J., Yu, Y. D., Zhang, Z., Murashkin, M., \& Valiev, R. Z. (2012). Deformation defects and electron irradiation effect in nanostructured $\mathrm{Al}-\mathrm{Mg}$ alloy processed by severe plastic deformation. Transactions of Nonferrous Metals Society of China, 22(8), 1810-1816.

Na, Y. S., Yeom, J. T., Park, N. K., \& Lee, J. Y. (2003). Simulation of microstructures for Alloy 718 blade forging using 3D FEM simulator. Journal of Materials Processing Technology, 141(3), 337342.

Obiko, J. O., Mwema, F. M., \& Bodunrin, M. O. (2019). Finite element simulation of X20CrMoV121 steel billet forging process using the Deform 3D software. SN Applied Sciences, 1(9), 1044.

Rasti, J., Najafizadeh, A., \& Meratian, M. (2011). Correcting the stress-strain curve in hot compression test using finite element analysis and Taguchi method. International Journal of Iron \& Steel Society of Iran, 8(1), 26-33.

Shi, R. X., \& Liu, Z. D. (2011). Hot deformation behavior of P92 steel used for ultra-Super-Critical power plants. Journal of Iron and Steel Research, International, 18(7), 53-58.

Wang, L., Liu, F., Cheng, J. J., Zuo, Q., \& Chen, C. F. (2015). Hot deformation characteristics and processing map analysis for Nickel-based corrosion resistant alloy. Journal of Alloys and Compounds, 623, 69-78.

Yang, C. C., \& Lin, X. Y. (2016). The forming analysis of two-stage extrusion for 1010 fastener. Journal of Mechanical Engineering and Automation, 6(3), 43-50.

Yang, Z., Zhang, F., Zheng, C., Zhang, M., Lv, B., \& Qu, L. (2015). Study on hot deformation behaviour and processing maps of low carbon bainitic steel. Materials \& Design (1980-2015), 66, 258-266.

Zaiemyekeh, Z., Liaghat, G. H., Ahmadi, H., Khan, M. K., \& Razmkhah, O. (2019). Effect of strain rate on deformation behavior of aluminum matrix composites with A12O3 nanoparticles. Materials Science and Engineering: A, 753, 276-284.

Zhang, Z. J., Dai, G. Z., Wu, S. N., Dong, L. X., \& Liu, L. L. (2009). Simulation of 42CrMo steel billet upsetting and its defects analyses during forming process based on the software DEFORM3D. Materials Science and Engineering: A, 499(1-2), 49-52.

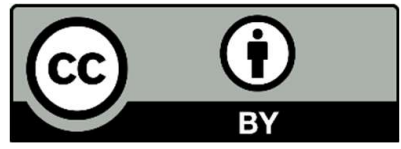

(C) 2020 by the authors; licensee Growing Science, Canada. This is an open access article distributed under the terms and conditions of the Creative Commons Attribution (CC-BY) license (http://creativecommons.org/licenses/by/4.0/). 